IZA DP No. 6249

Living Arrangements of the Elderly in China:

Evidence from CHARLS

Xiaoyan Lei

John Strauss

Meng Tian

Yaohui Zhao

December 2011 


\title{
Living Arrangements of the Elderly in China: Evidence from CHARLS
}

\author{
Xiaoyan Lei \\ Peking University \\ and IZA
}

John Strauss

University of Southern California

Meng Tian

Peking University

Yaohui Zhao

Peking University

and IZA

\section{Discussion Paper No. 6249 \\ December 2011}

IZA

P.O. Box 7240

53072 Bonn

Germany

Phone: +49-228-3894-0

Fax: +49-228-3894-180

E-mail: iza@iza.org

Any opinions expressed here are those of the author(s) and not those of IZA. Research published in this series may include views on policy, but the institute itself takes no institutional policy positions.

The Institute for the Study of Labor (IZA) in Bonn is a local and virtual international research center and a place of communication between science, politics and business. IZA is an independent nonprofit organization supported by Deutsche Post Foundation. The center is associated with the University of Bonn and offers a stimulating research environment through its international network, workshops and conferences, data service, project support, research visits and doctoral program. IZA engages in (i) original and internationally competitive research in all fields of labor economics, (ii) development of policy concepts, and (iii) dissemination of research results and concepts to the interested public.

IZA Discussion Papers often represent preliminary work and are circulated to encourage discussion. Citation of such a paper should account for its provisional character. A revised version may be available directly from the author. 
IZA Discussion Paper No. 6249

December 2011

\section{ABSTRACT \\ Living Arrangements of the Elderly in China: Evidence from CHARLS}

Recent increases in Chinese elderly living alone or only with a spouse has raised concerns about elderly support, especially when public support is inadequate. However, using rich information from the China Health and Retirement Longitudinal Study, we find that the increasing trend in living alone is accompanied with a rise in living close to each other. This type of living arrangement solves the conflicts between privacy/independence and family support. This is confirmed in further investigation: children living close by visit their parents more frequently. We also find that children who live far away provide a larger amount of net transfers to their parents, a result consistent with responsibility sharing among siblings. Having more children is associated with living with a child or having a child nearby, while investing more in a child's schooling is associated with greater net transfers to parents.

JEL Classification: J12, J14

Keywords: living arrangement, coresidence, proximity of children, CHARLS

Corresponding author:

Xiaoyan Lei

China Center for Economic Research

Peking University

Beijing 100871

China

E-mail: xylei@ccer.pku.edu.cn 


\section{Introduction}

Population is rapidly aging in China. In 2000, people 60 and older accounted for $10 \%$ of the population. The ratio rose to $13.3 \%$ in 2010 and is expected to reach $30 \%$ in 2050. Unlike developed countries where almost all elderly have access to social security, family has been the main source of support for Chinese elderly, especially in rural areas where the majority of Chinese elderly reside. In recent decades, however, the number of children has declined rapidly due partly to the draconian population policy implemented since the late 1970s, and rural young people have moved into cities in large numbers as part of the process termed "history's greatest migration in the world." These trends have cast doubt on the reliability of family as the provider of elderly support in China.

This concern is echoed by empirical evidence which shows that Chinese elderly are increasingly living alone or only with a spouse. Pamler and Deng (2008), using China Household Income Project (CHIPs) data collected in 1988, 1995, and 2002, show that persons 60 and older, especially those in urban areas, are increasingly more likely to live with their spouses rather than in intergenerational households with their children. They conjecture that the trend is due to the increasing availability of pensions which creates a basis for independence for the Chinese elderly as well as an additional source of income for traditional intergenerational households. Meng and Luo (2008), using the urban sample of CHIPs, also show that the fraction of elderly living in an extended family in urban China declined significantly over the study 
period. They attribute this trend to the housing reform during the 1990s, which increased housing availability and hence allowed elders who preferred to live alone to do so. Using population census data of 1982, 1990 and 2000, Zeng and Wang (2003) present a similar pattern and attribute it to tremendous fertility decline and significant changes in social attitudes and population mobility. They project that the rising trend of elderly with empty nests will persist in the future, which is confirmed in Figure 1, which shows that the rate of living alone or only with a spouse further declined in 2005 compared to 2000 .

[Figure 1 Insert Here]

What do we infer about the welfare of the elderly from this trend of living away from children? Most of the existing Chinese literature views it as rising misery on the part of the elderly because the elderly are not being supported or cared for. Benjamin, Brandt, and Rozelle (2000) find that elderly person living alone are worse off than those living in an extended household, and the implication is even stronger when we recognize that elderly in simple households also work more. Zimmer and Kwong (2003) are also less optimistic about this trend in reduction of family size. They concerns about whether traditional sources will decay, leading to an increase in the proportion of older adults with unmet needs. Sun (2002)'s research on China's contemporary old age support also suggests that living away from children does constrain them in receiving help with daily activities, and the family support system will face a great challenge in maintaining capacity to perform its supporting function 
in the near future given the continued demographic transition.

The same trend of elderly living alone has been noted in the United States where the proportion of elderly living independently increased markedly in the $20^{\text {th }}$ century (Costa, 1997; McGarry and Schoeni 2000; Engelhardt and Gruber 2005). While the literature has noted that living alone is associated with poverty, a higher level of depression symptoms and more persisting chronic diseases (Agree 1993; Saunders and Smeeding 1998; Victor et al. 2000; Kharicha et al. 2007; Wilson 2007; Greenfield and Russell 2010), the economic literature has in general viewed this trend as utility enhancing for the elderly and that independence or privacy is a normal good (Doty 1986; Martin 1989; Kotlikoff and Morris 1990; Mutchier and Burr 1991; Tomassini et al. 2004). For example, Costa (1998) finds that prior to 1940, rising income substantially increased demand for separate living arrangements, and therefore, was the most important factor enabling the elderly to live alone in the United States. McGarry and Schoeni (2000) analyze the causes of the increasing share of elderly widows living alone between 1940s and 1990s, and indicate that income growth, especially increased social security benefits, was the single most important factor causing the change in living arrangements, accounting for nearly two-thirds of the rise in living alone. With a more recent data from the Current Population Survey 1980-99, Engelhardt and Gruber (2005) find that living arrangements are still very income sensitive, particularly for widows and divorcees, and conclude from the results that privacy is valued by the elderly and their families. 
The different attitudes towards living arrangements between China and the U. S. can be understood in light of the relative importance of the family in providing support for the elderly. What we find lacking in the literature is that living alone and getting the support from the family are viewed as mutually exclusive, that living alone means not getting the help and in order to get the care from the family they need to live together.

Privacy is a normal good for both Americans and Chinese. In addition, it is a normal good for both elderly parents and their children. With the phenomenal economic growth that occurred in China over the past three decades, it is natural that parents and children may prefer to live separately. However, providing care to elderly parents and getting elderly care may also be normal good. In this paper, we examine how Chinese families reconcile these two objectives. With detailed information on where children live from the China Health and Retirement Longitudinal Study (CHARLS), we find that many Chinese elderly live alone or only with a spouse, but at the same time, most of them have a child living nearby to guarantee care when needed.

This type of living phenomenon is not a recent invention. Bian, Logan, and Bian (1998) find from data from two cities (Shanghai and Tianjin) in 1993 that although most elderly still lived with children, many of them also had children living nearby, providing regular non-financial assistance and maintaining frequent contact. Giles and $\mathrm{Mu}$ (2007) also provide some evidence on this tendency, though it is not the focus of 
their paper. Due mainly to lack of appropriate data, almost no other studies have followed this line of research to investigate this issue.

The first goal of this paper is to depict an updated and broad picture of the living arrangements of the Chinese elderly and to look at how many elderly parents living alone actually have access to children, i.e., have children living nearby. Secondly, we aim to shed some light on what determines the living arrangements of Chinese families with elderly parents, especially the proximity of children. Finally, we examine the tradeoff between living arrangements and other forms of elderly support including the frequency of visits and financial transfers. We find that the increasing trend in living alone is accompanied with a rise in living close to each other. This type of living arrangement solves the conflicts between privacy/independence and family support. This is confirmed in further investigation: children living close by visit their parents more frequently. We also find that children who live far away provide a larger amount of net transfers to their parents, a result consistent with responsibility sharing among siblings. Having more children is associated with living with a child or having a child nearby, while investing more in a child's schooling is associated with greater net transfers to parents.

The remainder of the paper is organized as follows. The next section describes our data. Section 3 presents the patterns of China's elderly living arrangements. Section 4 discusses the empirical results on the determination of elderly living arrangements. Section 5 concludes. 


\section{Data}

We use the CHARLS pilot data, which is described in detail in Zhao et al. (2009). CHARLS was designed after the Health and Retirement Study in the US as a broad-purposed social science and health survey of the elderly in Gansu and Zhejiang provinces. The pilot survey was conducted in July-September 2008. The CHARLS pilot sample is representative of people aged 45 and over, and their spouses, living in households in Gansu and Zhejiang provinces.

Zhejiang province is located in the developed coastal region, and Gansu, in the less developed western region. Gansu is the poorest and one of the most rural provinces in China, with per capita income less than half of Zhejiang province and $75 \%$ of the population being rural. On the other hand Zhejiang is one of the most dynamic and richest provinces, with a per capita income $50 \%$ higher than the Chinese national average. The pilot chose these two provinces to get at extremes within China. The full CHARLS will be national in scope and is scheduled to be fielded in 2011.

The sampling design of the 2008 wave of CHARLS was aimed to be representative of residents 45 and older in these two provinces. Within each province, CHARLS randomly selected 13 county-level units by PPS (Probability Proportional to Size), stratified by regions and urban/rural. Within each county-level unit, CHARLS randomly selects 3 village-level units (villages in rural areas and urban communities in urban areas) by PPS as primary sampling units (PSUs). Within each 
PSU, CHARLS then randomly selected 25 dwellings in rural and 36 in urban areas from a complete list of dwelling units generated from a mapping/listing operation. In situations where more than one age-eligible household lived in a dwelling unit, CHARLS randomly selected one. Final household sample size within a PSU depended on age-eligibility and response rates. Within each household, one person aged 45 and older is randomly chosen to be the main respondent and the spouse is automatically included. Based on this sampling procedure, 1 or 2 individuals in each household were interviewed depending on marital status of the main respondent. The total sample size was 2,685 individuals in 1,570 households. The CHARLS pilot experience was very positive. Overall response rate was $85 \% ; 79 \%$ in urban areas and $90 \%$ in rural areas. The response rate was about the same in the two provinces, $83.9 \%$ in Zhejiang and $85.8 \%$ in Gansu. These high response rates reflected the detailed procedures put in place to insure a high response to the survey.

Following the protocols of the Health and Retirement Studies (HRS) international surveys, the CHARLS main questionnaire in the 2008 survey consists of 7 modules, covering demographics, family background, health status (including physical and psychological health, cognitive functions, lifestyle, and behaviors), socioeconomic status (SES), and environment (community facilities) (Zhao et al. 2009). All data were collected in face-to-face, computer-aided personal interviews (CAPI).

In the family module, all CHARLS respondents were asked how many living children they have. For each child, CHARLS collected information on a variety of 
characteristics: sex, birth year and month, biological relationship with respondent, and residence. The residence of the child is categorized as follows: (1) this household, (2) adjacent dwelling or same courtyard, (3) another house in this village or community, (4) another village or community in this county or city, (5) another county or city in this province, (6) another province, and (7) abroad. This information enables us to describe the living arrangements in a more detailed way than the previous literature. Other information collected includes each child's education level, marital status, working status, occupation and number of children. At the respondent (parent) level, we have detailed demographic information, income and wealth measures, and rich health measures. More details about the variables we use are provided in Section 4. With this rich pool of information, we can use multivariate estimation to identify the determinants of elderly living arrangements and investigate joint decisions between parents and children.

\section{Patterns of Elderly Living Arrangement}

In this research, we define elderly living arrangements similar to the previous literature, but with special consideration to the proximity of child. That is, we divide elderly living arrangements into five categories: (1) living with one or more adult children, (2) living alone, but with one or more children in the same village or community, (3) living alone, but with one or more children in the same county, (4) living alone without any child in the same county, and (5) childless.

We restrict our attention to respondents and their spouses, at least one of whom is 
60 and older, who are considered old by the Chinese standard. Table 1 presents an overall picture of the elderly respondents' living arrangements in 2008. From this table, we can see that half $(50.8 \%)$ of all respondents are living with one or more adult children, which means that the other half (49.2\%) are living alone by the conventional definition. A small number of them (2\% of all) are childless (most of those men). Of those who have child(ren) but live alone, 59\% (27.7/47.2) have at least one adult child living in the same village/community, meaning that they do have access to the care from child(ren). Even for those without access to child in the same village, $79 \%$ $(15.4 / 19.5)$ have at least one child living in the same county. Only $4.1 \%$ of elderly with children, and $6.1 \%$ of all elderly do not have a child within the same county, in contrast to $49.2 \%$ if we disregard the proximity of children. This indicates that failing to account for the proximity of children will exaggerate the plight of the elderly in terms of care from children.

In general, women are more likely to live with or close to their children than men; those from Gansu and from rural areas are also more likely to do so than those from Zhejiang and urban areas. Meanwhile, men, those from Zhejiang and urban areas are more likely to be childless than their corresponding counterparts.

[Table 1 Insert Here]

Figure 2A shows the age patterns of elderly living arrangement by the conventional way. Two lines, one living alone or with spouse only, the other living with one or more adult child, are displayed. We see that the probability of living alone 
or only with spouse increases with age among CHARLS elderly respondents, and the probability of living with children declines correspondingly. If this figure was used to assess the welfare of the elderly, one would conclude that the Chinese elderly are miserable because they lose care as they age. ${ }^{1}$ Living alone does not necessarily decline with age. Based on a comprehensive dataset collected from 50 countries across five continents, the United Nations (2005) show that the likelihood of living alone actually increases at advanced ages. Logan, Bian and Bian (1998) argue that this decline reflects the normal process of maturation and growing independence of the child.

[Figure 2A Insert Here]

However, a different story emerges when we examine the pattern in more details. As shown in Figure 2B, the decline in the proportion of coresidency is fully compensated by the increasing share of proximate child(ren). The likely story is that when children mature and obtain independence from their parents, they do not abandon the parents. They move out but live nearby so that the care needs of parents are met. This is further evidence that looking at the proximity of children is valuable in understanding the welfare of the elderly.

\section{[Figure 2B Insert Here]}

\footnotetext{
${ }^{1}$ Note that this pattern differs from what we get from the census data (Figure 1), which presents a downward trend of living alone with age. The difference may be explained by the different definitions of "household". CHARLS is very meticulous about its definition of "households." Household members are defined as those families that live under the same roof, share food and other expenses. Census, on the contrary, has no clear definition of "households." The determination of a "household" is largely dependent on household registration. We think that our definition is more appropriate.
} 
Table 2 shows characteristics of the parents by whether they are living with a child, have a child living in the same county, or far away. Parents living with a child tend to be more heavily widowed, female, and have more children. They are more likely to be rural and to live in Gansu. Perhaps in consequence of the latter, they tend to be more illiterate. They also are more likely to report difficulties with either ADLs or IADLs.

[Table 2 insert here]

We then investigate the nearby children's supportive role in caring the elderly parents. Table 3 offers a detailed comparison between children living in the same household, children within the same county and children who live faraway. The coresident children are generally younger than those who are noncoresident. Parents are more likely to live with their youngest sons, and less likely to live with daughters. $78 \%$ of the elderly are living with in-laws. On average, coresident children have more grandchildren (less than 16 years old) than the noncoresident children.

\section{[Table 3 Insert Here]}

Table 4 shows the transfers provided by children with different living arrangements: living in the same county or far away. The probability of financially transferring to parents is higher for those living in the same county, but the amount of transfers to parents is far higher for those children who live far away. Getting transfers from parents is equally likely no matter how close the child lives, and the mean 
amount is not significantly different. As expected, the children who live nearby are more likely to visit their parents, possibly for the purpose of providing more help.

[Table 4 Insert Here]

To sum up the results in this section, we find that though half of the elderly CHARLS respondents live by themselves, most of them indeed have access to child assistance. The probability of elderly living alone increases as the elderly age, but it is mostly compensated by the presence of a child in the same village/community or county, and those nearby children pay more frequent visits to their elderly parents, and provide a higher amount of net transfers on average.

\section{Correlates of Elderly Living Arrangement}

In this section, we examine more systematically the predictors of elderly living arrangements. The rich information on parent and child characteristics together enables us to employ the data in two ways. The first is to group the data at the respondent (parent) level, which facilitates looking the effects of parental characteristics. The second one is grouping data at the child level, that is, to treat each child as one observation. This will enable us to use family fixed-effects to control for unobserved heterogeneity between families and focus on the job division between children.

We restrict our parent respondents to being aged 60 or above, with at least one child who is aged 25 and older and not a student. It is rarely the case that when we 
have data on a parent and the spouse, that they do not live together. To count them as two observations would not be appropriate so in those cases, we treat them as a single observation and use the main respondent's data. The parent-level sample is the 795 respondents and the corresponding child-level sample is the 2,602. Table 2 reports parental characteristics and Table 3 the children's. The average age of the elderly parents is 69 , with $52 \%$ male. Hence the average parent was born around 1940 , which means they would have been 40 in 1980, when the One-Child Policy started, and even in their 30 s during the family planning programs established during the 1970s. This absence of exposure to the stronger family planning policies is reflected in the number of surviving children, which is 3.5. Seventy-one percent of our parent sample are currently married, and $26 \%$ are widowed. Only $20 \%$ are from urban areas. Regarding health status, $70 \%$ of the elderly rate their health as being poor. Forty-five percent report having ADL or IADL difficulties. The education level of the elderly parents is generally very low. Fifty-one percent are illiterate, and $36 \%$ have a primary education either formally or informally. The annual pre-transfer income for the elderly household is 4,120 RMB, but with very large standard deviations. Ninety percent of the elderly parents currently own a house.

The average age of our child sample is around 42 . Among these children, $46 \%$ are daughters, $91 \%$ are married, and $81 \%$ are currently working. We divide sons into three groups, oldest sons, youngest sons, and sons that are neither oldest nor youngest. The first two groups may overlap, and a single male child could be both the oldest and youngest son the same time. The average number of their children younger than 16 , so 
grandchildren of our respondents, is 0.87 . The educational level of the children sample is much higher than their elderly parents. Only $17 \%$ are illiterate, $35 \%$ have completed primary school, $28 \%$ have a middle school education, and the remaining $19 \%$ have an education of high school and above.

In the following, we will separately report the results from estimation on coresidence and on proximity, and then examine the associations of living arrangement with visit frequencies and transfers.

\section{1._Correlates of Coresidence}

Whether or not the elderly live with their adult children can be influenced by various factors. The usual predictors include the care needs of the elderly, the preferences of both parents and children, and the potential care giver's resources. In our model, we proxy the care needs of the parents using their widowhood, self-reported general health or functional limitations. The preferences are represented by demographic characteristics and economic conditions of both parent and child. For example, the marital status of a child may significantly affect the parent's utility of living with the child due to in-law rivalry. Education of the children signifies the capacity and resources available from children. There may also be considerations of exchange of service for inheritance. Housing, for example, is an importance asset and children may care for parents by living together anticipating an inheritance.

Table 5 presents the results from OLS estimation with the parent-level data, in 
which the characteristics of each respondent's children are included at an aggregate level. The dependent variable in this model is defined as a dummy variable, which equals to 1 if the elderly is living with at least one adult child (aged 25+), and equals to 0 when the elderly is living alone or with a spouse only. We can see that after controlling for child age, parent's age is no longer significant. Widowed parents are more likely to coreside with their adult children and urban residents less so. Parents' education levels are not significantly related to living with a child. There is a nonlinear, positive correlation between income and coresidence, but not significant. $^{2}$ Parents owning a house are more likely to coreside with their children. Parents with ADL or IADL functional limitations are also more likely to coreside with one or more adult children. ${ }^{3}$ The child characteristics, averaged across siblings, are generally insignificant. There is a weak, positive relationship between children's education level and coresidence, but only jointly significant at $10 \%$.

\section{[Table 5 Insert Here]}

The model in Table 5 is limited in the sense that it cannot illustrate the exact effect of each specific child characteristics, and may be biased because of other unobservable factors. In Table 6, we provide an alternative model which controls for family fixed effects. This model allows us to examine more closely the influence of child characteristics on coresidence, and control for the family unobservables. The sample is further restricted to those children with at least one adult sibling. Results

\footnotetext{
${ }^{2}$ We model pre-transfer income as a linear spline with knot point at the median. The coefficient on the segment above the median is the slope (not the change in slope) over that segment.

${ }^{3}$ The health variables could be endogenous, so we do not attempt to interpret them as a causal relationship.
} 
show that (compared to those sons that are neither oldest nor youngest, ) the youngest son is more likely to live with their parents, and daughters are the least likely to do so. Married children are unlikely to coreside with parents, and children with more young offspring are more likely to do so. The likelihood of coresidence among those parents with higher-educated children is lower than those with less educated children, probably due to migration of children with more education.

\section{[Table 6 Insert Here]}

The above findings are consistent with existing literature (Meng and Luo 2004; Logan et al. 1998; McGarry and Schoeni 2000). We find that coresidence is largely dependent on elderly parents' needs. Those widowed elderly or those elderly with some physical health limitations are more likely to coreside with their children for care. Child may also save the housing expenses, and receive child care help by coresiding with their parents.

\subsection{Correlates of Multiple Living Arrangements}

Similar to the determination of coresidence, there are many factors that may affect children's living distance to their parents. We adopt a multinomial logit model to analyze the multiple choices on living arrangements. We set those without any child living in the same county as base group and examine the relative risk of coresidence and of having a child nearby. As reported in Table 7, the age effect is not significantly different across three types of living arrangements. Widowed elderly are much more 
likely to live with their children. The more children the elderly have, the more they are likely to coreside with an adult child or have an adult child close by. Owning a house has no effect either on the probability of coresidence nor of living close by. However, having higher pre-transfer income is associated with a greater chance of living with a child or having a child live nearby, with larger effects for poorer parents. Functional limitations of parents and being in poor health increase the probability of coresidence and of having a child nearby. People with more sons are more likely to live close to their children. An interesting finding is on the fraction of married children. When we look at coresidence as a binary choice (last section), we find that married children are less likely to live with their parents, though the coefficient is not significant. However, married children are more likely to live nearby, and significantly so. They are likely to live nearby so that they can continue to provide care when needed. Presence of more young grandchildren increases the probability of living nearby and of coresidece.

\section{[Table 7 Insert Here]}

\subsection{Living Arrangements, Visits and Transfers}

In this section, we examine the correlations between living arrangements and other forms of parent support: frequency of visits and financial transfers. As transfers can only be defined clearly among non-coresident children and their parents, we exclude coresident children from this estimation. Again the proximity of a child is defined as living within the same county as his/her parents'. Frequent visit is 
measured as whether the child is the most frequent one to visit his/her parents among his/her siblings. The CHARLS Pilot only asks about which child among those non-coresident, is the most frequent visitor. No time frequency information is available. Financial transfers are measured in two ways: 1) whether the child offers transfer to his/her elderly parents and 2) the net amount of transfers to parents.

The covariates for the financial transfer regressions include both parental and individual child characteristics. However, because of the way in which time transfers are asked, as most frequent visitor, we drop the parental characteristics save number of children. Having more children should decrease the odds that any one of them is the most frequent visitor, but it is not clear how variables such as parental pre-transfer income or education would affect which non-coresident child visits most frequently, unlike the amount or incidence of financial transfers, which should be associated with parental characteristics. ${ }^{4}$

As seen from Table 8, proximity to parents has strong positive effects on the probability of being the most frequently visiting child, replicating the bivariate results in Table 4. Another factor worth noting is that, the more siblings a child has, the less likely he/she frequently visits. The youngest son is more likely to visit as is a married child, possibly due to the presence of young grandchildren.

\section{[Table 8 Insert Here]}

The second and third pairs of columns in Table 8 report the estimation on whether

\footnotetext{
${ }^{4}$ In fact, when we include other parental characteristics they are not significant.
} 
a child provides transfer to his/her parents and on the net amount of transfers respectively. The incidence of providing transfers to parents is positively but the net amount negatively related to proximity. Hence those faraway children while visit less often, send more money when they make transfers. If the elderly parent coresides with another adult child, the nonresident child is less likely to provide help to parents, and the net amount is higher, but not significantly so. If the parent is widowed or has problems with ADLs or IADLs they tend to receive somewhat less transfers from non-coresident children, though we must remember that in these cases the parent is more likely to be living with one of their children. The higher education the child has, the more he/she is providing to the elderly parents and the more likely are the transfers. There is an obvious nonlinear effect of parental pre-transfer income. A child is slightly more likely to transfer to his/her parents if parental income is higher, but this is only true if parental income is less than the sample median and the association is only significant at $10 \%$. However for parents with pre-transfer incomes above the median, they get less net transfers if they have more income. Daughters provide less to their parents.

\section{Conclusions}

Previous literature has provided evidence that the Chinese elderly are increasingly more likely to live alone or with a spouse only. This has raised concerns on the elderly support, considering the lack of public transfers in current China. With detailed information on elderly living arrangements, this paper reveals that living close to 
parents has become an important way of providing elderly support while at the same time maintain independence/privacy of both parents and children. We conclude from the results that living alone is inadequate in describing the living arrangement of the elderly.

We also find the existence of responsibility sharing among siblings. Children live close to their parents frequently visit their parents, providing non-financial transfers to their parents; while those living faraway provide larger amount of financial transfers.

Investigating into the determinants of elderly living arrangements finds that living arrangements are affected by both parent and child characteristics. There is some evidence that parents with higher pre-transfer income are more likely to live with or near their adult children. Parents with an ADL or IADL difficulty are more likely to live with their children, meaning that coresidence is still functioning as an important source of elderly support.

Applying a family fixed-effects model to the child-level data, we have examined the within-family variations. One important finding is that youngest sons are more likely to live with their elderly parents, an interesting result different from the tradition of depending solely on oldest sons. Further research is needed to explore the underlying driving force of this transition. Daughters, as expected, are less likely to live with their parents, or to support them financially.

One very important set of findings has to do with correlations with the number of children. Parents with more living children are more likely to both be living with one of them, or nearby to them if not. Also having a parent live with one child 
reduces the burden on other children in terms of visiting and the likelihood of making a financial transfer. It is also the case that our results show that investing in educating their children more does have a payoff in terms of larger net transfers when the parent is older, although it is then less likely that the parent lives with well-educated child. As noted, it is the case that the older cohorts in this sample have on average 3.5 children; they were not exposed to the One Child Policy during most of their childbearing years. The average parent in our sample would have been born in 1940, so they would have been in their 30s even during the family programs established during the 1970s. It may be that cohorts younger than the ones studied here, who were exposed to the stronger family planning programs during their childbearing ages will be more constrained in their living arrangements than these cohorts; that is to be seen. On the other hand, if they invested more in their children's schooling that may offset, at least with regards to financial transfers. 


\section{References:}

Agree, E. M. 1993. Effects of demographic change on the living arrangements of the elderly in Brazil: 1960-1980. PhD Dissertation. Durham, NC: Duke University.

Benjamin, D., L. Brandt, and S. Rozelle. 2000. "Aging, wellbeing, and social security in rural northern China." Population and Development Review 26: 89-116.

Bian, F., J. R. Logan, and Y. Bian. 1998. "Intergenerational relations in urban China: Proximity, contact, and help to parents." Demography 35: 115-24.

Cameron, L. 2000. "The residency decision of elderly Indonesians: A nested logit analysis." Demography 37: 17-27.

Costa, D. L. 1998. Displacing the family. National Bureau of Economic Research. Chicago, IL: University of Chicago Press.

Doty, P. 1986. "Family care of the elderly: The role of public policy." The Milbank Quarterly 64: 34-75.

Edmonds, E. V. and K. Mammen, D. Miller. 2005. "Rearranging the Family? Income Support and Elderly Living Arrangements in a Low-Income Country." The Journal of Human Resources 40: 186-207.

Engelhardt, G. V. and J. Gruber. 2004. "Social security and the evolution of elderly poverty." NBER Working Paper Series, Vol. 10466.

Giles, J. and R. Mu. 2007. "Elderly Parent Health and the Migration Decisions of Adult Children: Evidence from Rural China." Demography 44: 265-88.

Greenfield, E. A. and D. Russell. 2010. "Identifying Living Arrangements That Heighten Risk for Loneliness in Later Life: Evidence From the US National Social Life, Health, and Aging Project." Journal of Applied Gerontology. Published online: 10.1177/0733464810364985

Kharicha, K., S. Iliffe, S. Illiffe, S. Harari, C. Swift, G. Gillmann, and A. Stuck. 2007. "Health risk appraisal in older people 1: are older people living alone an 'at-risk'group?" The British Journal of General Practice 57: 271-276.

Kotlikoff, L. J. and J. N. Morris. 1990. "Why don't the elderly live with their children? A new look." NBER Working Paper Series, Vol. 2734.

Lin, J. 1994. "Parity and Security: A Simulation Study of Old-Age Support in Rural China." Population and Development Review 20:423-48.

Logan, J. R., F. Bian, and Y. Bian. 1998. "Tradition and change in the urban Chinese family: The case of living arrangements." Social Forces 76: 851-82.

Martin, L. G. 1989. "Living arrangements of the elderly in Fiji, Korea, Malaysia, and the Philippines." Demography 26: 627-43.

McGarry, K. and R. F. Schoeni. 2000. "Social security, economic growth, and the rise in elderly widows' independence in the twentieth century." Demography 37: 221-36.

Meng, X. and C. Luo. 2008. "What determines living arrangements of the elderly in 
urban China." Pp267-286 in Inequality and Public Policy in China, Edited by B. A. Gustafsson, S. Li; and T. Sicular. Cambridge: Cambridge University Press.

Mutchier, J. E. and J. A. Burr. 1991. "A longitudinal analysis of household and nonhousehold living arrangements in later life." Demography 28: 375-90.

Palmer, E. and Q. Deng. 2008. "What has economic transition meant for the well-being of the elderly in China." Pp182-203 in Inequality and Public Policy in China, Edited by B. A. Gustafsson, S. Li; and T. Sicular. Cambridge: Cambridge University Press.

Smeeding, T. M. and P. Saunders. 1998. "How Do the Elderly in Taiwan Fare Cross-nationally?: Evidence from the Luxembourg Income Study Project." SPRC Discussion Paper: No. 81

Sun, R. 2001. "Old age support in contemporary urban China from both parents'and children's perspectives." Research on Aging. Published online: 10.1177/0733464810364985

Tomassini, C., K. Glaser, D. A. Wolf, M. I. Broese van Groenou, and E. Grundy. 2004. "Living arrangements among older people: an overview of trends in Europe and the USA." Further release of 2001 Census data: 1324-29.

Victor, C., S. Scambler, J. Bond, and A. Bowling. 2000. "Being alone in later life: loneliness, social isolation and living alone." Reviews in Clinical Gerontology 10: 407-17.

Wilson, B. 2007. "Historical evolution of assisted living in the United States, 1979 to the present." The Gerontologist 47(supplement): 8-22.

Zeng, Y. and Z. Wang. 2003. "Dynamics of Family and Elderly Living Arrangements in China: New Lessons Learned from the 2000 census." China Review 3: 95-119.

Zhao, Y., J. Strauss, A. Park and Y. Sun. 2009. China Health and Retirement Longitudinal Study User's Guide. China Center for Economic Research, Peking University.

Zimmer, Z. and J. Dayton. 2005. "Older Adults in Sub-Saharan Africa Living with Children and Grandchildren." Population Studies 59: 295-312.

Zimmer, Z. and J. Kwong. 2003. "Family size and support of older adults in urban and rural China: Current effects and future implications." Demography 40: $23-44$. 
Figure 1. Living Alone or With a Spouse Only

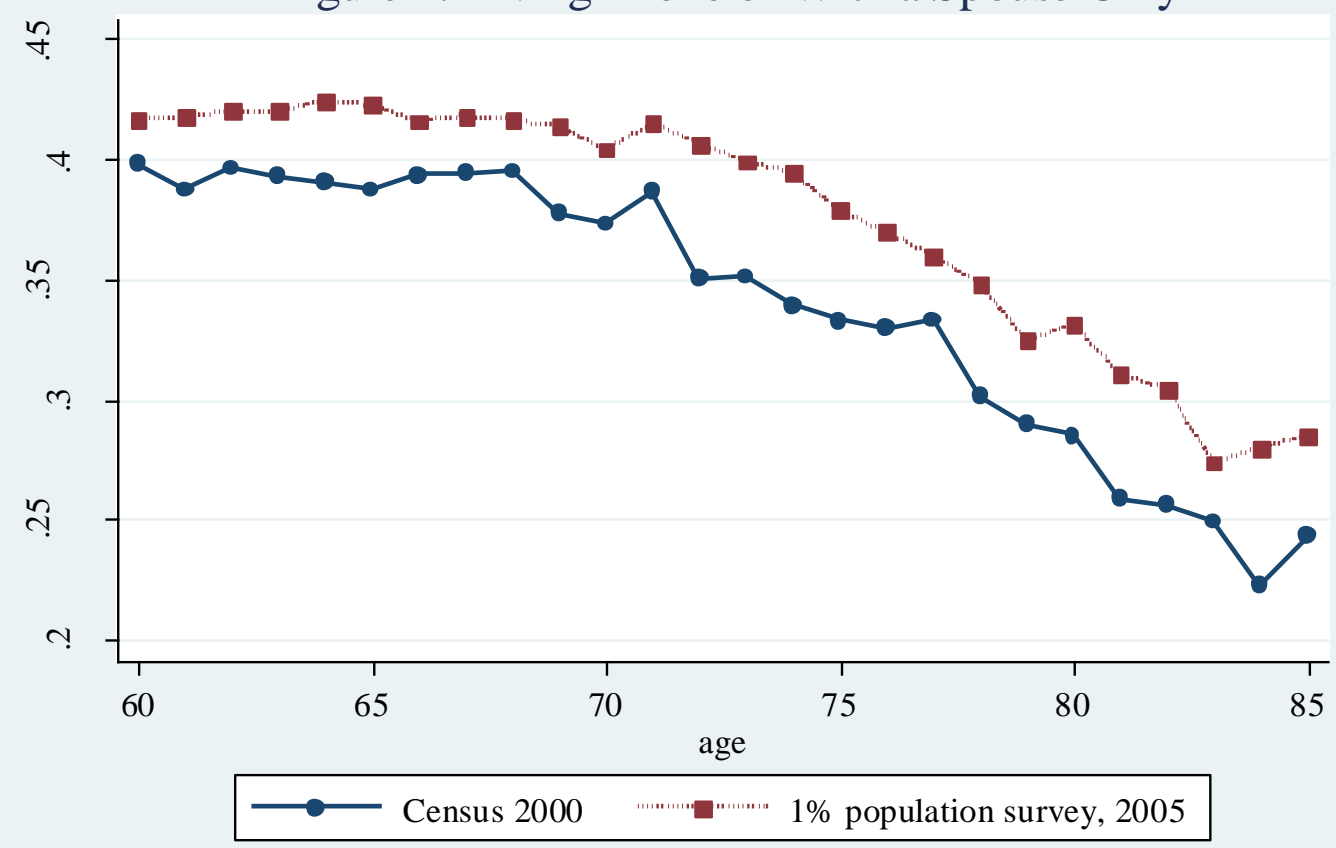

Sample: Elderly sample aged 60-85 from Census 2000 and 1\% population survey, 2005 


\section{Figure 2A. Living Arrangement of Elderly Household}

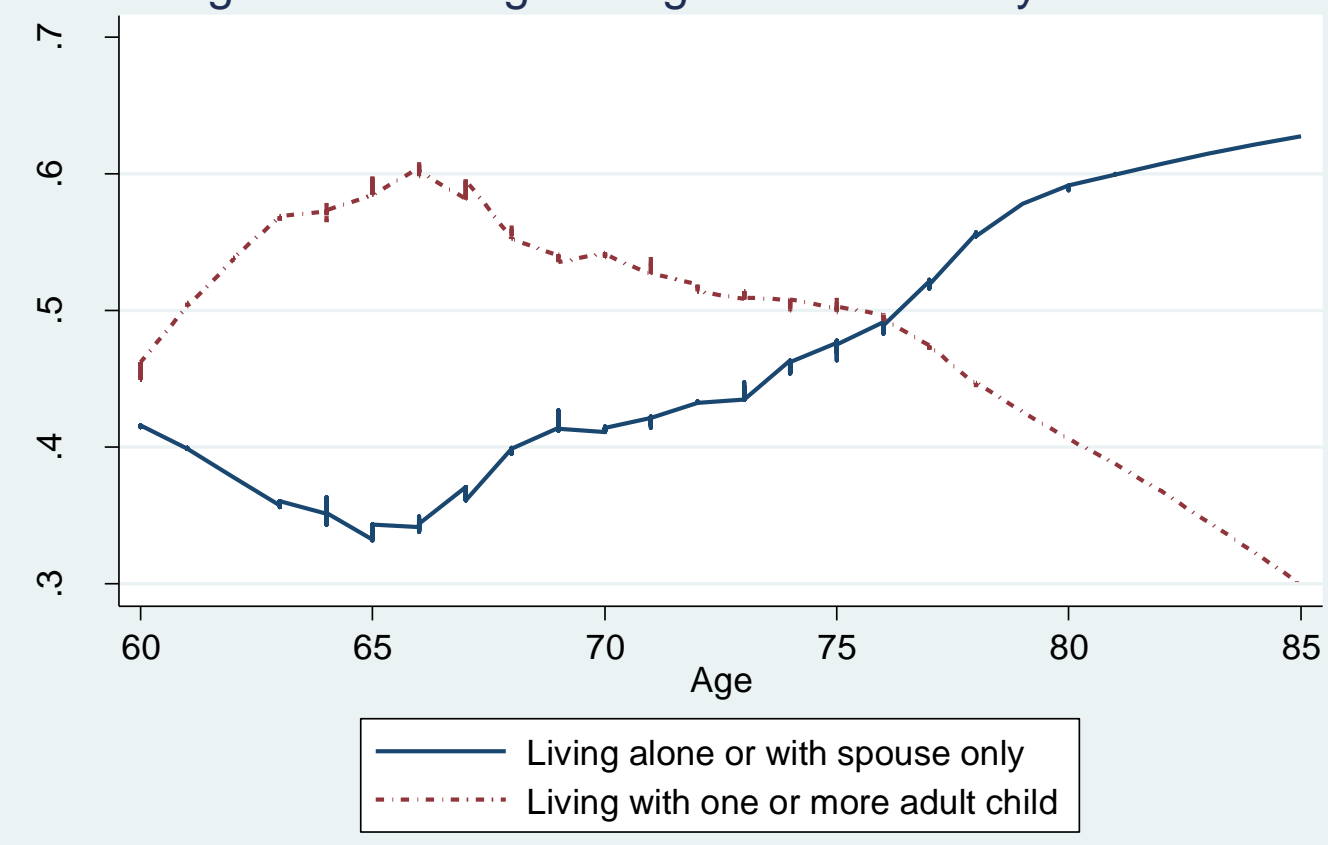

Sample: main respondent from CHARLS elderly household, bandwidth $=0.4$

Figure 2B. Living Arrangement and Proximity of Child

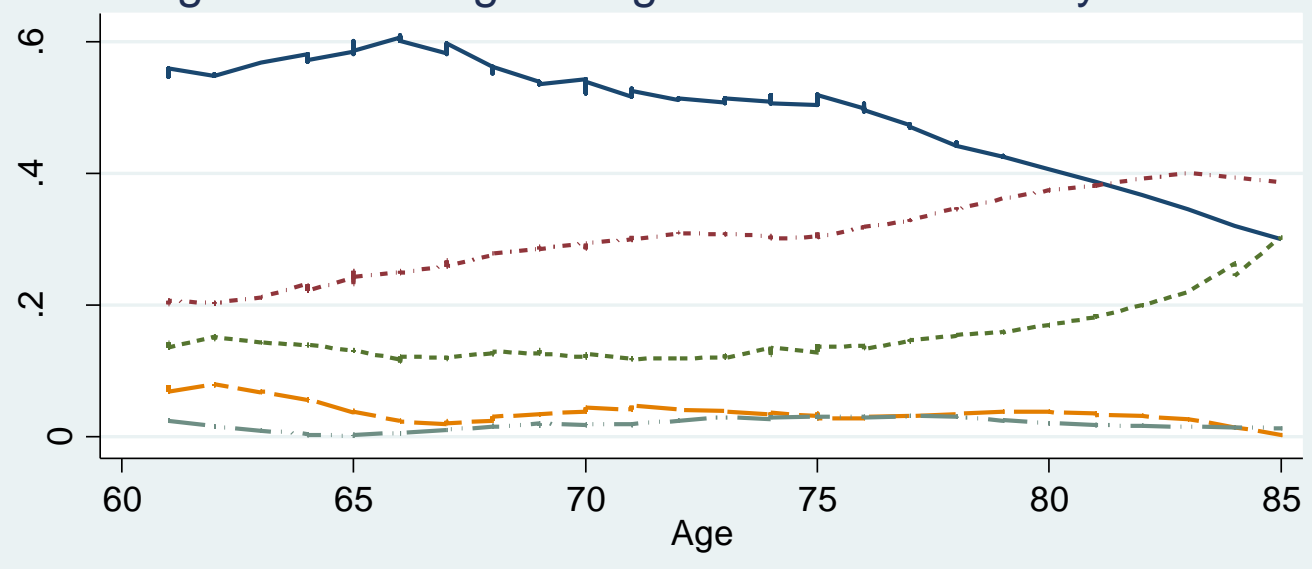

Living with one or more adult child
_..... Living alone, but with adult child in the village /community
_ _ - Living alone, no adult child in the county
- No adult child

Sample: main respondent from CHARLS elderly household, bandwidth $=0.4$ 
Table 1. Living Arrangement of Elderly Households (\%)

\begin{tabular}{|c|c|c|c|c|c|c|c|c|}
\hline & $\overline{\mathrm{OBS}}$ & $\overline{\text { Total }}$ & Female & Male & 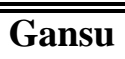 & Zhejiang & Rural & $\overline{\overline{\text { Urban }}}$ \\
\hline Living with one or more adult children & 412 & 50.8 & 51 & 50.6 & 61.2 & 41.8 & $\overline{54.4}$ & 35.3 \\
\hline $\begin{array}{l}\text { Live alone, but with one or more adult } \\
\text { children in the same village/community }\end{array}$ & 225 & 27.7 & 32.3 & 21.9 & 23.7 & 31.3 & 27.1 & 30.7 \\
\hline $\begin{array}{l}\text { Live alone, but with one or more adult } \\
\text { children in another village/community in } \\
\text { tho camo }\end{array}$ & 125 & 15.4 & 14.3 & 16.9 & 10.4 & 19.8 & 12.5 & 28.1 \\
\hline $\begin{array}{l}\text { Live alone without any child in the same } \\
\text { nounty }\end{array}$ & 33 & 4.1 & 2.2 & 6.5 & 4 & 4.1 & 3.6 & 5.9 \\
\hline No adult child & 16 & 2 & 0.2 & 4.2 & 0.8 & 3 & 2.4 & 0 \\
\hline Observations & & 811 & 455 & 356 & 376 & 435 & 658 & 153 \\
\hline
\end{tabular}

1) Sample: main respondent from CHARLS elderly households with at least one respondent 60 or above.

2) "No adult child" is defined as having no child 25 years old or above. 
Table 2. Parent Characteristics by Living Arrangements

\begin{tabular}{|c|c|c|c|c|c|}
\hline & All & $\begin{array}{l}\text { Living with } \\
\text { at least one } \\
\text { adult child }\end{array}$ & $\begin{array}{l}\text { Living alone } \\
\text { but with one } \\
\text { or more adult } \\
\text { child in the }\end{array}$ & $\begin{array}{l}\text { Living alone } \\
\text { but without } \\
\text { any adult } \\
\text { child in the }\end{array}$ & P-value \\
\hline \multicolumn{6}{|l|}{ Demographics } \\
\hline \multirow[t]{2}{*}{ Age } & 68.43 & 68.33 & 68.73 & 66.42 & 0.23 \\
\hline & {$[0.28]$} & {$[0.37]$} & {$[0.44]$} & {$[1.27]$} & \\
\hline \multirow[t]{2}{*}{ Male } & 0.43 & 0.44 & 0.39 & 0.7 & 0.00 \\
\hline & {$[0.02]$} & {$[0.02]$} & {$[0.03]$} & {$[0.08]$} & \\
\hline \multirow[t]{2}{*}{ Widowed } & 0.37 & 0.44 & 0.31 & 0.12 & 0.00 \\
\hline & {$[0.02]$} & {$[0.02]$} & {$[0.02]$} & {$[0.06]$} & \\
\hline \multirow[t]{2}{*}{ \# of Children } & 3.52 & 3.61 & 3.57 & 1.97 & 0.00 \\
\hline & {$[0.06]$} & {$[0.08]$} & {$[0.08]$} & {$[0.17]$} & \\
\hline \multirow[t]{2}{*}{ Zhejiang } & 0.53 & 0.44 & 0.63 & 0.55 & 0.00 \\
\hline & {$[0.02]$} & {$[0.02]$} & {$[0.03]$} & {$[0.09]$} & \\
\hline \multirow[t]{2}{*}{ Urban } & 0.19 & 0.13 & 0.26 & 0.27 & 0.00 \\
\hline & {$[0.01]$} & {$[0.02]$} & {$[0.02]$} & {$[0.08]$} & \\
\hline \multicolumn{6}{|l|}{ Education } \\
\hline \multirow[t]{2}{*}{ Illiterate } & 0.55 & 0.57 & 0.53 & 0.39 & 0.10 \\
\hline & [0.02] & {$[0.02]$} & {$[0.03]$} & [0.09] & \\
\hline \multirow[t]{2}{*}{ Primary } & 0.35 & 0.34 & 0.36 & 0.36 & 0.93 \\
\hline & {$[0.02]$} & {$[0.02]$} & {$[0.03]$} & {$[0.08]$} & \\
\hline \multirow[t]{2}{*}{ Middle school } & 0.06 & 0.05 & 0.07 & 0.12 & 0.25 \\
\hline & {$[0.01]$} & {$[0.01]$} & {$[0.01]$} & {$[0.06]$} & \\
\hline \multirow[t]{2}{*}{ High school and above } & 0.04 & 0.04 & 0.05 & 0.12 & 0.30 \\
\hline & {$[0.01]$} & {$[0.01]$} & {$[0.01]$} & {$[0.06]$} & \\
\hline \multicolumn{6}{|l|}{ Income Wealth } \\
\hline \multirow[t]{2}{*}{ House Ownership } & 0.88 & 0.92 & 0.81 & 0.91 & 0.00 \\
\hline & {$[0.01]$} & {$[0.01]$} & {$[0.02]$} & {$[0.05]$} & \\
\hline \multirow{2}{*}{$\begin{array}{l}\text { Pre-transfer Income } \\
\qquad(1000 \mathrm{RMB})\end{array}$} & 5.30 & 5.08 & 5.52 & 5.77 & 0.80 \\
\hline & {$[0.36]$} & {$[0.47]$} & {$[0.58]$} & {$[1.71]$} & \\
\hline \multicolumn{6}{|l|}{ Health } \\
\hline \multirow[t]{2}{*}{ Poor SRH } & 0.26 & 0.28 & 0.25 & 0.16 & 0.18 \\
\hline & {$[0.02]$} & {$[0.02]$} & {$[0.02]$} & {$[0.06]$} & \\
\hline \multirow[t]{2}{*}{ ADL\&IADL Difficulties } & 0.51 & 0.59 & 0.44 & 0.28 & 0.00 \\
\hline & {$[0.02]$} & {$[0.02]$} & {$[0.03]$} & {$[0.08]$} & \\
\hline Observations & 795 & 412 & 350 & 33 & \\
\hline
\end{tabular}

1) Sample: Main respondent of CHARLS elderly households (with at least one respondent 60 or above).

2) P-value of testing whether the means are equal are provided in the last column.

3) Robust standard errors in brackets. 


\begin{tabular}{|c|c|c|c|c|c|}
\hline & All & Coresident & $\begin{array}{l}\text { Nearby } \\
\text { Child }\end{array}$ & $\begin{array}{l}\text { Non-Nearby } \\
\text { Child }\end{array}$ & P-value \\
\hline \multicolumn{6}{|l|}{ Demographics } \\
\hline \multirow[t]{2}{*}{ Child Age } & 41.93 & 39.09 & 43.02 & 40.49 & 0.00 \\
\hline & {$[0.25]$} & {$[0.40]$} & {$[0.28]$} & {$[0.50]$} & \\
\hline \multirow[t]{2}{*}{ Oldest Son } & 0.15 & 0.22 & 0.13 & 0.16 & 0.00 \\
\hline & {$[0.01]$} & {$[0.02]$} & {$[0.01]$} & {$[0.02]$} & \\
\hline \multirow[t]{2}{*}{ Youngest Son } & 0.27 & 0.59 & 0.17 & 0.3 & 0.00 \\
\hline & {$[0.00]$} & {$[0.02]$} & {$[0.01]$} & {$[0.02]$} & \\
\hline \multirow[t]{2}{*}{ Daughter } & 0.46 & 0.12 & 0.55 & 0.47 & 0.00 \\
\hline & {$[0.01]$} & {$[0.02]$} & {$[0.01]$} & {$[0.02]$} & \\
\hline \multirow[t]{2}{*}{ Fraction Married } & 0.91 & 0.78 & 0.96 & 0.85 & 0.00 \\
\hline & {$[0.01]$} & {$[0.02]$} & {$[0.00]$} & {$[0.02]$} & \\
\hline \multirow[t]{2}{*}{ \# of child younger than 16} & 0.87 & 1.30 & 0.77 & 0.91 & 0.00 \\
\hline & {$[0.04]$} & {$[0.09]$} & {$[0.05]$} & {$[0.09]$} & \\
\hline \multicolumn{6}{|l|}{ Education } \\
\hline \multirow[t]{2}{*}{ Illiterature } & 0.17 & 0.12 & 0.19 & 0.11 & 0.00 \\
\hline & {$[0.01]$} & {$[0.02]$} & {$[0.01]$} & {$[0.02]$} & \\
\hline \multirow[t]{2}{*}{ Primary Education } & 0.35 & 0.33 & 0.37 & 0.29 & 0.02 \\
\hline & {$[0.01]$} & {$[0.02]$} & {$[0.01]$} & {$[0.02]$} & \\
\hline \multirow[t]{2}{*}{ Middle School } & 0.29 & 0.38 & 0.26 & 0.29 & 0.00 \\
\hline & {$[0.01]$} & {$[0.02]$} & {$[0.01]$} & {$[0.02]$} & \\
\hline \multirow[t]{2}{*}{ HighSchool } & 0.14 & 0.13 & 0.13 & 0.16 & 0.32 \\
\hline & {$[0.01]$} & {$[0.02]$} & {$[0.01]$} & {$[0.02]$} & \\
\hline \multirow[t]{2}{*}{ College and Above } & 0.06 & 0.03 & 0.05 & 0.15 & 0.00 \\
\hline & {$[0.01]$} & {$[0.01]$} & {$[0.01]$} & {$[0.02]$} & \\
\hline Observations & 2681 & 468 & 1779 & 434 & \\
\hline
\end{tabular}

1) Sample: adult children (aged 25 or above) from CHARLS elderly households.

2) Nearby child is defined as living outside of the household but within the same county.

3) Children are defined in four groups: oldest son, youngest son, sons who are neither oldest nor youngest, daughter.

4) Clustered standard errors at family level in brackets.

5) P-value of testing whether the means are equal are provided in the last column. 
Table 4. Transfer and Visit by Living Arrangement

\begin{tabular}{ccccc}
\hline \hline & Overall & $\begin{array}{c}\text { Live in the } \\
\text { county }\end{array}$ & $\begin{array}{c}\text { Do not live in } \\
\text { the county }\end{array}$ & P-value \\
\hline Transfer to Parents & & & & \\
Fraction Positive & 0.60 & 0.61 & 0.55 & 0.04 \\
& {$[0.02]$} & {$[0.02]$} & {$[0.03]$} & \\
Average amount & 1200.28 & 1077.12 & 1754.98 & 0.02 \\
& {$[123.03]$} & {$[135.31]$} & {$[254.97]$} & \\
Tranfer From Parents & & & & \\
Fraction Positive & 0.03 & 0.03 & 0.03 & 0.82 \\
& {$[0.01]$} & {$[0.01]$} & {$[0.01]$} & \\
Average amount & 66.99 & 54.98 & 121.08 & 0.50 \\
& {$[21.99]$} & {$[16.05]$} & {$[96.43]$} & \\
Net Transfer & & & & \\
Average amount & 704.66 & 646.95 & 941.19 & 0.10 \\
& {$[79.58]$} & {$[87.83]$} & {$[163.75]$} & \\
Frequent Visit & 0.20 & 0.22 & 0.14 & \\
Observations & {$[0.01]$} & {$[0.01]$} & {$[0.02]$} & 0.00 \\
\hline \hline
\end{tabular}

1) Sample: non-coresident adult children from CHARLS elderly households (with at least one respondent 60 or above).

2) Transfer amounts to parent and from parent are defined as the average amount conditional on

3) Net transfer is defined as the amount of transfer from child to parents minus the amount of

4) Clustered standard errors at family level in brackets.

5) P-value of testing whether the means are equal are provided in the last column. 
Table 5. Parent-Level OLS Estimation on Coresidence

\begin{tabular}{|c|c|c|}
\hline Parent Characteristics & Coef. & S.E. \\
\hline Age & 0.059 & $(0.043)$ \\
\hline Age2/100 & -0.040 & $(0.030)$ \\
\hline Male & 0.028 & $(0.041)$ \\
\hline Widowed & $0.156^{* * *}$ & $(0.039)$ \\
\hline Urban & $-0.158 * *$ & $(0.065)$ \\
\hline \multicolumn{3}{|l|}{ Education } \\
\hline Primary & 0.019 & $(0.042)$ \\
\hline Middle school & -0.085 & $(0.088)$ \\
\hline High school and above & -0.049 & $(0.085)$ \\
\hline $\mathrm{p}$-value for education & 0.593 & \\
\hline \# of Children & $0.030 *$ & $(0.016)$ \\
\hline House Ownership & $0.175^{* * *}$ & $(0.050)$ \\
\hline \multicolumn{3}{|l|}{ Pre-transfer Income (1000 RMB) } \\
\hline For PTI in $1-1 / 2$ & 0.016 & $(0.034)$ \\
\hline For PTI in $1 / 2-1$ & $0.004 *$ & $(0.003)$ \\
\hline p-value for pre-transfer income & 0.149 & \\
\hline \multicolumn{3}{|l|}{ Health } \\
\hline SRH poor & -0.011 & $(0.042)$ \\
\hline ADL\&IADL Difficulties & $0.077 *$ & $(0.042)$ \\
\hline $\mathrm{p}$-value for health & 0.178 & \\
\hline \multicolumn{3}{|l|}{ Child Characteristics } \\
\hline $\begin{array}{l}\text { Average age } \\
\text {. }\end{array}$ & -0.017 & $(0.026)$ \\
\hline Average age ${ }^{\wedge} 2$ & 0.000 & $(0.000)$ \\
\hline Fraction of being male & -0.001 & $(0.060)$ \\
\hline \# children under 16 & 0.001 & $(0.012)$ \\
\hline Fraction married & -0.119 & $(0.084)$ \\
\hline \multicolumn{3}{|l|}{ Maximum education } \\
\hline Primary school & 0.033 & $(0.080)$ \\
\hline Middle School & $0.133^{*}$ & $(0.078)$ \\
\hline High School & 0.088 & $(0.082)$ \\
\hline College and Above & 0.025 & $(0.089)$ \\
\hline p-value for child education & 0.096 & \\
\hline Constant & -1.503 & $(1.297)$ \\
\hline County Dummy & Yes & \\
\hline Observations & 795 & \\
\hline R-square & 0.234 & \\
\hline
\end{tabular}

1) Sample are respondents of elderly housheolds who have at least one child aged 25 and above.

2) Robust standard errors are reported.

3) $* * * \mathrm{p}<0.01, * * \mathrm{p}<0.05, * \mathrm{p}<0.1$. 
Table 6. Child-Level Estimation on Coresidence (Fixed-Effect)

\begin{tabular}{lcc}
\hline \hline Child Characteristics & Coef. & S.E. \\
\hline Age & -0.004 & $(0.008)$ \\
Age^2 & 0.001 & $(0.008)$ \\
Oldest son & 0.001 & $(0.030)$ \\
Youngest son & $0.134^{* * *}$ & $(0.028)$ \\
Daughter & $-0.197^{* * *}$ & $(0.023)$ \\
\# children under 16 & $0.026^{*}$ & $(0.013)$ \\
Married & $-0.163^{* * *}$ & $(0.043)$ \\
Education & & \\
$\quad$ Primary school & -0.024 & $(0.028)$ \\
$\quad$ Middle school & 0.015 & $(0.034)$ \\
$\quad$ High school & -0.034 & $(0.040)$ \\
College and above & $-0.148^{* * *}$ & $(0.045)$ \\
$\quad$ p-value for child education & 0.000 & \\
R-Square & 0.211 & \\
Observations & 2,602 & \\
\hline \hline
\end{tabular}

1) Sample includes adult children of 25 and older who have at least one parent no younger than 60 and who have at least one adult sibling.

2) Robust standard errors are reported.

3) $* * * \mathrm{p}<0.01, * * \mathrm{p}<0.05, * \mathrm{p}<0.1$ 
Table 7. Parent-Level Multinomial Logit Estimation on Living Arrangements

\begin{tabular}{|c|c|c|c|c|}
\hline \multirow[b]{2}{*}{ Parent Characteristics } & \multicolumn{2}{|c|}{ In the Same Household } & \multicolumn{2}{|c|}{ Within the County } \\
\hline & Relative Risk & Z-score & Relative Risk & Z-score \\
\hline Age & 1.507 & 0.840 & 0.937 & -0.140 \\
\hline Age2 & 0.732 & -0.890 & 1.003 & 0.010 \\
\hline Male & 0.505 & -1.410 & 0.466 & -1.550 \\
\hline Widowed & $5.823 * *$ & 2.520 & 2.646 & 1.420 \\
\hline Urban & 0.894 & -0.150 & 2.196 & 1.070 \\
\hline \multicolumn{5}{|l|}{ Education } \\
\hline Primary education & 1.723 & 1.020 & 1.720 & 1.020 \\
\hline Middle school & 0.598 & -0.620 & 0.959 & -0.050 \\
\hline High school and above & 0.999 & 0.000 & 1.244 & 0.210 \\
\hline $\mathrm{p}$-value for education & 0.791 & & 0.791 & \\
\hline \# of children & $2.857 * * *$ & 3.680 & $2.818 * * *$ & 3.700 \\
\hline Owning house & 0.934 & -0.090 & 0.341 & -1.420 \\
\hline \multicolumn{5}{|l|}{ Pre-transfer Income (1000 RMB) } \\
\hline For PTI in $0-1 / 2$ & 1.525 & 1.000 & $1.266^{* * * *}$ & 4.410 \\
\hline For PTI in $1 / 2-1$ & 1.028 & 0.940 & 1.014 & 0.500 \\
\hline $\mathrm{p}$-value for income & 0.000 & & 0.000 & \\
\hline \multicolumn{5}{|l|}{ Health } \\
\hline SRH poor & 1.581 & 0.780 & 1.511 & 0.710 \\
\hline ADL\&IADL Difficulty & 2.239 & 1.540 & 1.366 & 0.600 \\
\hline p-value for health & 0.053 & & 0.053 & \\
\hline \multicolumn{5}{|l|}{ Child Characteristics } \\
\hline Average age & 0.826 & -0.590 & 0.963 & -0.110 \\
\hline Average age ${ }^{\wedge} 2$ & 1.002 & 0.550 & 1.001 & 0.330 \\
\hline Fraction male & 0.638 & -0.710 & 0.544 & -0.950 \\
\hline Fraction married & 2.717 & 1.290 & $10.68 * * *$ & 2.980 \\
\hline \# of young grandchild & $1.342 * * *$ & 2.750 & $1.309 * * *$ & 2.850 \\
\hline \multicolumn{5}{|l|}{ Maximum education } \\
\hline Primary education & 0.690 & -0.350 & 0.593 & -0.480 \\
\hline Middle school & 0.954 & -0.050 & 0.569 & -0.540 \\
\hline High school & 1.021 & 0.020 & 0.761 & -0.250 \\
\hline College and Above & 0.211 & -1.430 & 0.182 & -1.470 \\
\hline $\mathrm{p}$-value for child education & 0.293 & & 0.293 & \\
\hline Constant & $1.23 \mathrm{e}-05$ & & 8.951 & \\
\hline County dummy & Yes & & & \\
\hline Observations & 795 & & & \\
\hline
\end{tabular}

1) Sample are respondents of 60 and older who have at least one child aged 25 and above.

2) Robust standard errors are reported.

3) Base group: those without any children in the same county.

4) $* * * \mathrm{p}<0.01, * * \mathrm{p}<0.05, * \mathrm{p}<0.1$ 
Table 8. Vists, Transfer, and Living Arrangment

\begin{tabular}{|c|c|c|c|c|c|c|}
\hline & \multicolumn{2}{|c|}{ Frequent Visit } & \multicolumn{2}{|c|}{ Transfer to Parent } & \multicolumn{2}{|c|}{ Net Amount of Transfer } \\
\hline & Coef. & $\mathrm{SE}$ & Coef. & $\mathrm{SE}$ & Coef. & SE \\
\hline Live in the same county & $0.104 * * *$ & $(0.020)$ & $0.058 *$ & $(0.030)$ & $-354.206^{* *}$ & $(150.312)$ \\
\hline child & - & - & $-0.095 * * *$ & $(0.033)$ & 152.480 & $(147.865)$ \\
\hline Parent Characteristics & - & - & & & & \\
\hline Age & - & - & 0.031 & $(0.034)$ & -41.954 & (118.257) \\
\hline $\mathrm{Age}^{\wedge} 2$ & - & - & -0.028 & $(0.024)$ & 16.792 & $(83.723)$ \\
\hline Male & - & - & 0.024 & $(0.035)$ & 278.399 & $(188.447)$ \\
\hline Widowed & - & - & -0.022 & $(0.034)$ & $-224.853^{*}$ & (117.063) \\
\hline Urban & - & - & -0.016 & $(0.058)$ & 186.762 & $(351.916)$ \\
\hline Education & - & - & & & & \\
\hline Primary & - & - & 0.011 & $(0.036)$ & 93.341 & $(147.021)$ \\
\hline Middle school & - & - & 0.065 & $(0.064)$ & 4.516 & $(255.768)$ \\
\hline High school and above & - & - & 0.024 & $(0.081)$ & -490.508 & $(425.870)$ \\
\hline p-value for education & & & 0.796 & & 0.642 & \\
\hline \# of children & $-0.042 * * *$ & $(0.005)$ & $0.030 * *$ & $(0.014)$ & 10.997 & $(47.113)$ \\
\hline House ownership & - & - & -0.059 & $(0.043)$ & -554.852 & $(466.176)$ \\
\hline \multicolumn{7}{|l|}{ Pre-transfer Income (1000 RMB) } \\
\hline For PTI 1-1/2 & - & - & $0.009 *$ & $(0.006)$ & 39.987 & $(27.346)$ \\
\hline For PTI 1/2-1 & - & - & -0.002 & $(0.002)$ & $-11.238 *$ & $(6.684)$ \\
\hline p-value for income & & & 0.212 & & 0.162 & \\
\hline \multicolumn{7}{|l|}{ Health } \\
\hline SRH poor & - & - & 0.023 & $(0.037)$ & 171.121 & $(202.309)$ \\
\hline ADL\&IADL difficulties & - & - & -0.038 & $(0.038)$ & $-259.960 *$ & $(157.604)$ \\
\hline p-value for health & & & 0.516 & & 0.257 & \\
\hline \multicolumn{7}{|l|}{ Child Characteristics } \\
\hline Child age & -0.003 & $(0.008)$ & $0.039 * * *$ & $(0.011)$ & 73.083 & $(48.499)$ \\
\hline Child age ${ }^{\wedge} 2$ & 0.006 & $(0.009)$ & $-0.032 * * *$ & $(0.011)$ & $-77.660 *$ & $(44.616)$ \\
\hline Oldest son & 0.038 & $(0.034)$ & -0.026 & $(0.035)$ & 135.077 & $(380.791)$ \\
\hline Youngest son & $0.097 * * *$ & $(0.033)$ & 0.015 & $(0.031)$ & -26.485 & $(205.346)$ \\
\hline Daughter & -0.023 & $(0.024)$ & 0.007 & $(0.030)$ & $-278.171 * *$ & $(124.766)$ \\
\hline Married & $0.068 * *$ & $(0.034)$ & $0.093 *$ & $(0.049)$ & 174.142 & $(349.614)$ \\
\hline \# of Children $<16$ & -0.001 & $(0.013)$ & -0.008 & $(0.018)$ & 65.772 & $(59.158)$ \\
\hline \multicolumn{7}{|l|}{ Education } \\
\hline Primary education & 0.016 & $(0.025)$ & $0.127 * * *$ & $(0.035)$ & -118.360 & $(148.875)$ \\
\hline Middle school & 0.005 & $(0.026)$ & $0.127 * * *$ & $(0.043)$ & 54.706 & (148.394) \\
\hline High school & 0.019 & $(0.032)$ & $0.232 * * *$ & $(0.045)$ & $922.125^{* *}$ & $(451.807)$ \\
\hline College and above & 0.020 & $(0.041)$ & $0.344 * * *$ & $(0.055)$ & $727.455^{* *}$ & $(333.681)$ \\
\hline p-value for child education & & & 0.000 & & 0.054 & \\
\hline Constant & 0.236 & $(0.179)$ & -1.542 & $(1.136)$ & $1,485.350$ & $(3,747.487)$ \\
\hline County Dummy & Yes & & Yes & & Yes & \\
\hline Observations & 2,213 & & 2,213 & & 2,213 & \\
\hline R-squared & 0.066 & & 0.144 & & 0.080 & \\
\hline
\end{tabular}

1) Sample includes non-coresident children of 25 and older with at least one parent no younger than 60 .

2) Clustered standard errors at family level are reported.

3) $* * * \mathrm{p}<0.01, * * \mathrm{p}<0.05, * \mathrm{p}<0.1$. 